\title{
Renin-Angiotensin-Aldosterone System Inhibitors in Patients with Covid-19
}

André Feldman ${ }^{1, *}$, Guilherme D’Andréa Saba Arruda ${ }^{1}$, Olga Ferreira de Souza²

\section{ORCID IDs}

Feldman A (D) https://orcid.or/0000-0002-3941-1216

Arruda GASA (D) https://orcid.org/0000-0003-3770-1559

Souza OF (D) https://orcid.org/0000-0001-8722-7504

\begin{abstract}
COVID-19 is a new disease caused by the Sars-CoV-2 virus and the vast majority of patients have symptoms similar to a flu-like syndrome. A small portion of those infected ends up being hospitalized and may develop with the most severe presentation of the disease. Data from Chinese series report that hypertension appears to be a condition that imposes a greater risk of unfavorable evolution of patients. Some studies have reported that Sars-CoV-2 uses the angiotensin-converting enzyme to access its target cells. There are theories that differ about the protective or harmful role that drugs that act in the renin angiotensin aldosterone system in these patients. A British study suggests that patients using angiotensin-converting enzyme inhibitors had a lower incidence of severe forms of the disease. Another study carried out a retrospective and multicenter analysis showing that mortality was lower in the group that had used the drugs when compared to the other group (3,7 vs. 9,8\%; $p=0,01)$. The various hypotheses raised through pathophysiology are not yet able to really predict the best course of action for patients using drugs that act on the renin angiotensin system. Thus, a randomized study becomes important to try to answer definitively and with a high degree of reliability to this question.
\end{abstract}

KEYWORDS: Renin-angiotensin system; COVID-19; Angiotensin-converting enzyme.

1. Rede D'Or São Luiz - São Paulo (SP), Brazil.

2. Rede D'Or São Luiz - Rio de Janeiro (RJ), Brazil.

*Correspondonding author: andre.feldman@hotmail.com

Received: Jun 12, 2020 | Accepted: Jul 01, 2020 


\section{INTRODUCTION}

COVID-19 is a new disease caused by the Sars-CoV-2 virus initially reported in Wuhan province, in China, which took on worldwide proportions and gained pandemic status in March $2020^{1}$. High transmissibility rate and low real lethality rate (approximately $2 \%)^{2}$. The measured lethality may vary according to the region analyzed, mainly due to the number of diagnostic tests performed.

The vast majority of patients have symptoms similar to a flu-like syndrome, such as: dry cough, runny nose, fever and general malaise. A small portion of those infected ends up being hospitalized and may evolve with the most severe presentation of the disease, with pneumonia and acute respiratory syndrome. To date, several drugs are still being tested to achieve a better prognosis of severe forms of the disease ${ }^{1,2}$.

Data from Chinese series report that hypertension appears to be a condition that imposes a greater risk of unfavorable evolution of patients. Some hypotheses have already been raised and are being studied to explain this possible correlation.

The presence of cardiac complications can occur in up to $23 \%$ of patients. The presentations can be as distinct as possible from arrhythmias, myocarditis, pericarditis, Takotsubo's disease and type 2 infarctions. It is important to note that patients with previous cardiovascular diseases have a greater chance of unfavorable evolution ${ }^{3}$.

\section{Infection mechanism}

Despite some divergences, some studies have reported that Sars-CoV-2 uses the angiotensin-converting enzyme (ACE2) to access its target cells ${ }^{4-6}$.

ACE2 is a carboxypeptidase that preferably removes carboxy-terminal hydrophobic amino acids. Through the cleavage of a single Angiotensin I residue (Angio I), Ang 1-9 is generated or by the cleavage of the original Ang 1-7 Angiotensin II, whose vasodilation, antiproliferation and anti-fibrosis effects are opposed to the effects of Angiotensin II generated by $\mathrm{ACE} 2^{7}$.

A recent study showed that ACE2 is highly expressed in the mouth and tongue, thus facilitating the penetration of the virus into the host. In healthy human lungs, ACE2 is expressed in the lower portions of type I and type II cells of the alveolar epithelium. After infection by Sars-CoV-2, its entry into the cell occurs through the connection between the glycoprotein S, expressed in the virus envelope, and ACE2, present on the alveolar surface. The link between Sars-CoV-2 and ACE2 stimulates clathrin-dependent endocytosis, which promotes the internalization of the entire Sars-CoV-2 and ACE2 complex through its fusion in the cell membrane ${ }^{8}$.

Once inside the cell, Sars-CoV-2 exploits the endogenous transcriptional machinery of pneumocytes to replicate and spreads throughout the lung. ${ }^{8}$. With the infection, most ciliated cells in the alveolus interrupt their airway cleaning activities leading to the progressive accumulation of debris and fluids causing, in its highest degree, acute respiratory syndrome ${ }^{8}$.

Since the affinity of ACE2 binding has been shown to be a major determinant of Sars-CoV-2 infectivity, experiments on the interaction between virus and receptor at atomic levels of spatial resolution have been conducted to identify the specific domain of Glycoprotein S present in the viral envelope involved in the interaction between Sars-CoV-2 and ACE2 9 .

A better understanding of this process may provide a unique opportunity to develop specific therapies aimed at blocking the connection between Sars-CoV-2 and ACE2, minimizing the infectivity mechanism of this virus.

\section{Experimental studies}

The renin-angiotensin-aldosterone system has already been extensively studied within cardiology, since several drugs used in clinical practice have a close relationship with this axis ${ }^{10,11}$.

In 2003, a type of severe acute respiratory syndrome spread rapidly around the world. A new type of coronavirus (Sars-CoV-2) has been identified as the pathogen responsible for the outbreak, which can cause severe acute pneumonia, with a high potential for lethality. In this context, ACE2 has been potentially identified as the Sars-CoV receptor. In the past epidemic, there was a lot of fear about the impacts that this infection could cause for people, within the health system, as well as economic and social implications. 
Experimental studies have shown that genetically modified mice without the expression of ACE2 had fewer copies of the viruses, as well as less lung damage, suggesting that ACE2 is actually a crucial SARS receptor in vivo that is essential for effective replication ${ }^{12-14}$. From these data it is believed that the renin-angiotensin system plays an important role in the severity of severe acute lung injury ${ }^{13,14}$.

There are theories that diverge about the protective or harmful role that drugs of the class of angiotensin-converting enzyme (ACE) inhibitors or angiotensin receptor blockers (ARB) can cause. The theory that suggests harm is based on the possibility that the use of blockers of the renin-angiotensin system would increase ACE2 levels and facilitate the entry of the virus into cells, promoting an increase in infection in its most severe form. The presence of ACE2 in abundance in alveolar cells makes the lung the preferred organ for the entry of the virus, associating it with a plausible relationship between receptors and respiratory manifestations $\mathrm{s}^{3,15}$. On the other hand, another theory states that the use of these drugs can mitigate COVID-19, as it attenuates the acute pulmonary impairment mediated by Angio II. With the use of ACEi or ARB, less production of Angiotensin II occurs. It is worth remembering that Angio II has a vasoconstriction effect, inflammation and a prothrombotic effect (possibly increasing PAI-1 levels) through its binding to the angiotensin II type 1 receptor. Thus, its lower production would minimize these harmful effects. In addition, blocking the renin-angiotensin system leads to increased production of Ang (1-7) and activation of the Mas receptor. The latter has an anti-inflammatory, antifibrotic, antioxidant and anti-apoptotic effect, which may protect the severe form of the disease ${ }^{17}$.

There are still many doubts about the inhibition of the renin-angiotensin aldosterone system in the expression of ACE2. One of these studies, which evaluated the intravenous infusion of angiotensin-converting enzyme inhibitors in patients with coronary artery disease, did not influence the production of angiotensin (1-7), which arouses interest if ACE inhibitors actually have effects on metabolism of ACE2- Angiotensin II ${ }^{11,12}$.

\section{Human studies}

A British study evaluated patients diagnosed with COVID-19 whose primary outcome was defined as death or admission to the intensive care unit (ICU) within 7 days of symptom onset. In this cohort, 205 patients were analyzed and, of these, 53 patients reached the primary outcome. Among patients who used angiotensin-converting enzyme (ACEI) inhibitors, $14 \%$ died or needed an ICU versus $29 \%$ of patients who did not use this type of medication. Logistic regression findings suggest that patients using angiotensin-converting enzyme inhibitors had a lower incidence of severe forms of the disease. This effect is mitigated when adjustments are made for gender and age. The limitation of the study is due to the small size of its sample, because it is a single center and the short period of clinical follow-up ${ }^{16}$.

Another study carried out a retrospective and multicenter analysis (nine centers in Hubei, China) that included 1,128 patients with hypertension diagnosed with COVID-19, including 188 patients using ACE inhibitors / ARB who were compared to 940 patients without using these drugs. Mortality was lower in the group that had used the drugs when compared to the other group (3,7 vs. 9,8\%; $\mathrm{p}=0,01)^{17}$.

A retrospective analysis of 1,178 patients, with a mean age of 55.5 years, showed that the total hospital mortality was $11 \%$. The prevalence of hypertension was $30.7 \%$. The specific mortality of the hypertensive group was $21.3 \%$. The severity of the evolution was not influenced, and there was no difference according to the medication used in the treatment ${ }^{18}$.

The various hypotheses raised through pathophysiology are not yet able to really predict the best course of action to be taken in patients using ACEI and ARB. Thus, a randomized study becomes important to try to answer definitively and with a high degree of reliability to this question ${ }^{19}$.

\section{CONCLUSIONS}

The renin-angiotensin system appears to be closely involved in Sars-CoV-2 processes. To date, the guidance of all cardiology societies has been unanimous in maintaining the recommendation not to suspend these medications in patients with COVID-19 until stronger data can definitively clarify this issue. 


\section{REFERENCES}

1. Zhou P, Yang X-L, Wang X-G, Hu B, Zhang L, Zhang W, et al. A pneumonia outbreak associated with a new coronavirus of probable bat origin. Nature. 2020;579:270-3. https://doi.org/10.1038/s41586-020-2012-7

2. Guan W-J, Ni Z-Y, Hu Y, Liang W-H, Ou C-Q, He J-X, et al. Clinical characteristics of coronavirus disease 2019 in China. N Engl J Med. 2020;382:1708-20. https://doi.org/10.1056/NEJMoa2002032

3. Yang X, Yu Y, Xu J, Shu H, Xia J, Liu H, et al. Clinical course and outcomes of critically ill patients with Sars-CoV-2 pneumonia in Wuhan, China: a single-centered, retrospective, observational study. Lancet Respir Med. 2020;8(5):475-81. https://doi.org/10.1016/S22132600(20)30079-5

4. Hoffmann M, Kleine-Weber H, Schroeder S, Krüger N, Herrler T, Erichsen S, et al. Sars-CoV-2 cell entry depends on ACE2 and TMPRSS2 and is blocked by a clinically proven protease inhibitor. Cell. 2020;181(2):271-80. https://doi.org/10.1016/j.cell.2020.02.052

5. Yan R, Zhang Y, Li Y, Xia L, Guo Y, Zhou Q. Structural basis for the recognition of the Sars-CoV-2 by full-length human ACE2. Science. 2020;367(6485):1444-8. https://doi.org/10.1126/science.abb2762

6. Liu Z, Xiao X, Wei X, Li J, Yang J, Tan H, et al. Composition and divergence of coronavirus spike proteins and host ACE2 receptors predict potential intermediate hosts of Sars-CoV-2. J Med Virol. 2020;92(6):595-601. https://doi.org/10.1002/jmv.25726

7. Ye M, Wysocki J, William J, Soler MJ, Cokic I, Batlle D. Glomerular localization and expression of angiotensin-converting enzyme 2 and angiotensin-converting enzyme: implications for albuminuria in diabetes. J Am Soc Nephrol. 2006;17(11):3067-75. https://doi. org/10.1681/ASN.2006050423

8. Zumla A, Chan JFW, Azhar El, Hui DSC, Yuen K-Y. Coronaviruses - drug discovery and therapeutic options. Nat Rev Drug Discov. 2016;15(5): 327-47. https://doi.org/10.1038/nrd.2015.37

9. Wan Y, Shang J, Graham R, Baric RS, Li F. Receptor recognition by the novel coronavirus from Wuhan: an analysis based on decadelong structural studies of SARS coronavirus. J Virol. 2020;94(7). https://doi.org/10.1128/JVI.00127-20

10. Chen L, Li X, Chen M, Feng Y, Xiong C. The ACE2 expression in human heart indicates new potential mechanism of heart injury among patients infected with Sars-CoV-2. Cardiovasc Res. 2020;116(6):1097-100. https://doi.org/10.1093/cvr/cvaa078

11. Kuba K, Imai Y, Rao S, Gao H, Guo F, Guan B, et al. A crucial role of angiotensin converting enzyme 2 (ACE2) in SARS coronavirusinduced lung injury. Nat Med. 2005;11(8):875-9. https://doi.org/10.1038/nm1267

12. Imai Y, Kuba K, Rao S, Huan Y, Guo F, Guan B, et al. Angiotensin-converting enzyme 2 protects from severe acute lung failure. Nature. 2005;436(7047):112-6. https://doi.org/10.1038/nature03712

13. Zheng Y-Y, Ma Y-T, Zhang J-Y, Xie X. COVID-19 and the cardiovascular system. Nat Rev Cardiol. 2020;17(5):259-60. https://doi. org/10.1038/s41569-020-0360-5

14. Vincent JL, Taccone FS. Understanding pathways to death in patients with COVID-19. Lancet Respir Med. 2020;8(5):430-2. https:// doi.org/10.1016/S2213-2600(20)30165-X

15. Vaduganathan M, Vardeny O, Michel T, McMurray JJV, Pfeffer MA, Solomon SD. Renin-Angiotensin-Aldosterone System Inhibitors in Patients with Covid-19. N Engl J Med. 2020;382(17):1653-9. https://doi.org/10.1056/NEJMsr2005760

16. Bean DM, Kraljevic Z, Searle T, Bendayan R, Pickles A, Folarin A, et al. ACE-inhibitors and Angiotensin-2 Receptor Blockers are not associated with severe SARS- COVID19 infection in a multi-site UK acute Hospital Trust Eur J Heart Fail 2020;22(6):967-974. https:// doi.org/10.1002/ejhf.1924

17. Zhang P, Zhu L, Cai J, Lei F, Qin J-J, Xie J, Liu Y-M, et al. Association of inpatient use of angiotensin converting enzyme inhibitors and angiotensin II receptor blockers with mortality patients with hypertension hospitalized with COVID-19. Circ Res. 2020;126(12):167181. https://doi.org/10.1161/CIRCRESAHA.120.317134

18. $1 \mathrm{Li} \mathrm{J}$, Wang $\mathrm{X}$, Chen J, Zhang H, Deng A. Association of renin-angiotensin system inhibitors with severity or risk of death in patients with hypertension hospitalized for Coronavirus disease 2019 (COVID-19) infection in Wuhan, China. JAMA Cardiol. 2020;5(7):825-30. https://doi.org/10.1001/jamacardio.2020

19. Danser AHJ, Epstein M, Batlle D. Renin- Angiotensin System Blockers and the COVID-19 Pandemic. Hypertension. 2020;75:1382-5. https://doi.org/10.1161/HYPERTENSIONAHA.120.15082 